\title{
On the Reform and Innovation in Higher Vocational Education Physical Education Teaching Method
}

\author{
Mao-Song Zhang \\ School of Tourism Commerce Vocational of Jiangx University, Nanchang 330100, China. \\ 77620981@qq.com
}

Keywords: Education reform and innovation; public sports; Vocational Colleges.

\begin{abstract}
With China's economic and social development continued steadily, vocational colleges in recent years, the overall size of the school, its mission, teaching philosophy, teaching methods as a whole have varying degrees of improvement, but is limited by the PE teachers in vocational colleges in our country "Research" relatively few teachers, their teaching philosophy teaching methods, teaching methods and teacher and so far in today's developed countries, vocational colleges, higher vocational colleges and Learning public Physical contradictions become increasingly prominent, especially in teaching Teaching methods are difficult to adapt to the current PE of Higher Vocational Education, Higher Vocational College in Jiangxi this paper as an example, analyzes the necessity of the local Vocational Physical Teaching method reform and innovation, discusses the public sports reform and innovation strategy, and then to promote the effective development of vocational education and to enhance the overall quality of students has a positive effect.
\end{abstract}

\section{Introduction}

As the Sports is an exotic of education, the development of life than the traditional national sport is shorter, including teaching philosophy, teaching methods, teaching methods and so is coming from abroad, and combined with their actual situation of reform. Practice has repeatedly proved, vocational colleges physical education to improve personal physical and mental quality of students has a significant role to promote the comprehensive development of students' comprehensive quality and, therefore, higher vocational colleges must pay attention to public sports teaching, teaching methods should actively carry out reform and innovation, can meet the needs of social development, to change the traditional single teaching mode to enhance the effectiveness of teaching.

\section{PE Teaching Methods in Higher Vocational Education Reform and Innovation}

Not only quality education of higher vocational colleges should actively carry out reform and innovation in public physical education teaching methods, and quality education to cultivate virtue, wisdom, labor-round development of human resources, and thus be able to see the Reform and Innovation in Public PE Teaching Method is enhance public physical education in higher vocational colleges effect practical needs. At present, China is in a critical period of reform, society needs a large number of high-level personnel is needed is a comprehensive ability of people, in a sense, the quantity and quality of talent for the modernization of great significance. Development of China's modernization of higher education demands, education should not only pay attention to now instill knowledge, should pay more attention to students' psychological training, will train, train skills, etc., and public physical education in higher vocational colleges innovation side, it is possible to enhance the fundamental physical fitness of students, improve their ability to deal with various issues, strengthen their willpower. Therefore, the strengthening of public sports reform of teaching methods to improve teaching effectiveness of public sports, is the need of the times. Words and short, carry out reform and innovation Public method Vocational College Physical Education for cultivating high-quality integrated talent-round development has a positive effect. 


\section{PE Teaching Methods in Higher Vocational Education Reform and Innovation Strategy}

Public Physical Education in Vocational Colleges goal is to guide students to master knowledge related to sports, to enhance the physical fitness of students, to develop students awareness of lifelong sports, students with their career-related sports skills, therefore, innovation PE Teaching Method in Higher Vocational College to carry out as a center to promote literacy and enhance the students' comprehensive ability.

3.1 emphasis on Public Physical Education Patterns inspire and guide the formula

In public physical education, teachers must be able to recognize the examination-oriented education idea backwardness, breaking the one-sided emphasis on the concept of examinationoriented education, teaching reform and instill the concept can be fully integrated individual needs of students, the future development needs to carry out heuristic guide teaching to enhance students' intrinsic motivation to participate in sports by enlightening guidance and teaching to enhance students' awareness of independent participation in physical exercise to enhance the students' ability to learn the sport cooperation. By enlightening guidance and teaching there for students to students in classroom physical education study guide, so that students can consciously learn sports knowledge, mastering sports skills, capable of binding to the students 'practical and improve awareness of participation in sports students, improve students' lifelong sports forging consciousness to enhance students 'sports and cultural levels, and promote the development of students' comprehensive literacy.

3.2 to carry out the integrated teaching mode

For the current public Vocational College Physical Education, many students did not grasp the actual physical exercise science, physical education learning result is not ideal. Therefore, teachers should be able to guide students feel the value of physical exercise science, sports science so that students feel the effects of exercise. Vocational College PE Teachers recommend the use of teaching methods of teaching to do integration of teaching, effective use of morning exercises, sports, classroom teaching and extra-curricular sports activities in sports teaching methods to teach so that students in the activity gradually master the correct way to exercise, acquire the relevant action essentials, thereby enabling students to combine their own situation to use science alone exercise to enhance physical activity, but also need to carry out public sports fitness, entertainment combine to guide students to actively participate in sports activities, students can change the traditional passive learning active learning or independent study.

\section{3 take the club teaching methods}

Public Physical Teaching in Higher to actively break the traditional teaching mode, teaching methods to take the club, the sports teaching and student recreational activities together to promote the development of students' motivation to learn the sport. Currently, many vocational colleges are able to recognize the importance of club teaching methods; teaching methods while the club also attaches great importance to the perfect combination of students' sports interests and skills, through the club teaching, Students Learning Initiative Choice stronger. Of club teaching mode, active teaching lively atmosphere, students learn not only sports club can possess a wealth of sports knowledge, but also to grasp the superb sports skills, more deeply felt the charm of physical exercise, students can exercise joy through sport mood; sports club teaching methods to improve the students' enthusiasm to participate in sports practice, physical education teaching effect is obvious. Therefore, in public sports reform and innovation in higher vocational colleges, teaching mode should pay attention to the club, the club can be performed according to the school building, the student, so as to promote the upgrading of Public Physical Teaching.

3.4 PE teaching to public scientific target design

Higher education should be able to market-oriented, in order to promote student success as the goal of employment, training highly skilled personnel through vocational education. Physical education in vocational goal setting, it is also required as a basis for public sports teaching goal setting. Physical education students to be able to develop a comprehensive literacy, improve their physical health as the goal, to education through sport means to develop the potential of students, 
improve students 'ability to adapt to society, and promote the development of students' physical and mental health. Sports goal is to be able to promote students' physical and mental health development as the main objective, professional and able to focus on the characteristics of higher vocational colleges to improve their professional ability to set goals, sports public only on teaching the scientific goal setting in order to guide the sports teaching activities with the goal of science to promote the teaching of PE courses generated.

3.5 Public Physical Education students should pay attention to the ability and willpower

At this stage, only higher vocational colleges enhancing students' skills, students on the basis of comprehensive literacy teaching, can we truly cultivate social needs talents. Vocational colleges according to their actual situation, make full use of existing school sports teaching resources, can improve students' ability to target the rich sports program, students combine occupational characteristics, goals, there are plans to guide students sports learning, so that the public physical education can be effectively developed. For example, in teaching to train through the pole vault, climbing, obstacle race project and other projects students to challenge themselves the courage and guts, to train students in endurance and perseverance through the marathon, to be run through the relay, volleyball, football, basketball and other students the sense of cooperation and the spirit of cooperation, to foster through tennis, table tennis, badminton and other projects students excellent psychological quality, only carried out by public sports instructional design, in order to promote the development of students' comprehensive literacy.

3.6 Public Physical Education to be able to be combined with the students' professional needs

In public Physical Education in Higher Vocational teaching to be able to match students vocational need to be combined, if it is to improve students' sports learning initiative to promote the development of physical education, improve their professionalism, support for students effective employment and entrepreneurship. Therefore, the public should be able to combine physical education with students' career needs, target selection and design of teaching content. For example, for computer science, applied electronics specialty, accountancy student, they need to have high dexterity in order to better complete the task. Thus, in physical education training students to choose some projects finger flexibility, for example, a finger exercise, wrist exercises, etc., improve their professionalism. As another example, tourism management students need to have a sense of service, training students to be able to have a sense of obedience, therefore, to select some of the larger technical difficulty of sports, such as dance, aerobics, etc., culture in training students' sense of obedience, neat concept of unity. Select the content of physical education students should be capable of binding together expertise through teaching, improve students 'professional practice ability, ability to adapt to the post, and promote the development of students' professionalism.

3.7 to develop a scientific way of physical examination

Physical examination to gain a foothold round development of students in order to promote students' comprehensive capacity building as the basis for setting the assessment project. Vocational colleges should be able to use a variety of evaluation system based on the student's professionalism, evaluation of students overall literacy. Now, many vocational colleges are based on credit evaluation of students, the main contents of the evaluation is to develop sports sports sports knowledge skills. Develop a scientific sports assessment methods, the assessment content, to break the single content of assessment methods, assessment content, it is possible to cultivate the students' sports habits, awareness of lifelong sports participation as a center, the development of the assessment project, to be able to put students to participate in sports attitudes and participation in sports activities integrated into the evaluation system to go, can the teacher evaluation and student self-evaluation, mutual evaluation between students combine the evaluation of students, through a variety of assessment methods, and promote the comprehensive quality of students' sports development of.

\section{Conclusion}

To sum up, in the new era of knowledge society requires not only talent, but talent comprehensive ability, the number of personnel, quality has become the measure of a country's 
comprehensive over important indicator. In this context, higher vocational colleges should pay attention to not only cultural classes education courses, but also need to focus on physical education teaching. There are still some problems in the traditional public physical education, the impact of the effective training of personnel. Under the new situation, Vocational Physical Education Reform and innovation is necessary, by way of vocational colleges should be able to approach the public physical education innovation, to enhance the quality of personnel training. Only in this way, higher vocational education to meet the needs of the times, can really train more talents.

Fund Project: Jiangxi College of Humanities and Social Sciences 2014 Project of the Year (TY1415)

\section{References}

[1] Mao Zhenming .sports pedagogy [M] Beijing: Higher Education Press, 2005.

[2] Zhong Qiquan .modern teaching theory [M] Beijing: Education Science Press, 1992.

[3] Zhoudeng .Song School of Physical Education [M]. Higher Education Press, 2004.

[4] Huang Fu. On the whole learning process Modern Teaching [M]. Education Science Press, 2003.

[5] Jianguo.A Comparative Study of Traditional Sports and Modern Sports Teaching Methods of teaching methods [J]. Nanjing Institute of Physical Education (Natural Science), 2009,8 (4): 102103.

[6] Peng Xiaowei, Yang Guoqing. To re-analysis and recognition category on the current method of Physical Education[J]. Shenyang Institute of Physical Education, 2010,29 (4): 93-95. 